\title{
POLÍTICA DE EXTENSÃO NA PERSPECTIVA COLABORATIVA PELA FORMAÇÃO DOCENTE
}

\author{
Thalita Cunha Motta; Ilane Ferreira Cavalcante; Elizama Lemos \\ thalitacmotta@gmail.com; ilane.cavalcanti@ifrn.edu.br; elizama.lemos@ifrn.edu.br \\ Instituto Federal de Educação, Ciência e Tecnologia do Rio Grande do Norte \\ DOI: $10.15628 /$ rbept.2018.6885
}

Artigo submetido em dez/2017 e aceito em mar/2018

\section{RESUMO}

O presente artigo versa sobre a política de extensão na formação docente desenvolvida num Instituto Federal de Educação, Ciência e Tecnologia, conforme previsto nas leis n. 9.394/96 e n. 11.892/2008, assim como no Projeto Político Pedagógico (IFRN, 2012). Partimos da análise do trabalho de extensão na perspectiva de colaboração pedagógica entre o IFRN e escolas públicas do estado do Rio Grande do Norte, desenvolvido desde 2013, no IFRN pelo Grupo de Pesquisa em Multireferencialidade, Educação e Linguagem (GPMEL), por meio de oficinas e/ou minicursos construídos a partir das demandas identificadas em cada escola parceira, articulado com o ensino, a pesquisa e a educação profissional. Damiani (2008), Freire (2015), Sancho (2006) são basilares na construção dessa perspectiva de extensão. Assim, docentes das várias instituições, estudantes de licenciaturas e do ensino fundamental e médio interagem numa troca de experiências e saberes, construindo diferentes habilidades e novas perspectivas de ensinoaprendizagem. Dessa forma, o trabalho colaborativo permite a articulação de conhecimentos teóricos e metodológicos da formação profissional docente, bem como tem permitido a expansão das perspectivas de profissionalização, no sentido de trabalho em conjunto, ações negociadas e relações de diálogo e de compartilhamento. Tais elementos são, ao mesmo tempo, grandes desafios da profissionalização docente na atualidade e indispensáveis para o fortalecimento do trabalho educacional democrático, público, gratuito e de qualidade.

Palavras-chave: Extensão, Trabalho colaborativo, Tecnologias e educação, Formação de professores. 


\title{
Politics of extension in a collaborative perspective for teacher formation
}

\begin{abstract}
The following article discusses about the extension politics on the academic qualification process developed in a Federal Institute of Education, Science and Technology, as foreseen by the laws n. 9.346/96 and n. 11.892/2008, likewise the Political and Pedagogical Project (IFRN, 2012). We started out by analyzing, with a perspective in pedagogical collaboration, the extension work developed, since 2013, between IFRN and the public schools of Rio Grande do Norte by the Research Group in Multireferentiality, Education and Language (GPMEL), through workshops and minicourses based on the schools' demands. Damiani (2008), Freire (2015), Sancho (2006) are fundamental in the construction of this extension perspective. Therefore, teachers from various institutions, undergraduates and students interact in an exchange of experience and knowledge, unearthing new abilities in teaching-learning. That way, the collaborative effort allows the articulation of theoretical and methodological knowledge, and also shows new perspectives of professionalization, in the sense of co-working, negotiation and dialogue. The aforementioned elements are, simultaneously, challenging for the current professional processes and indispensable in the path to fortify a good and free educational work.
\end{abstract}

Keywords: Extension, Collaborative work, Technologies and education, Teacher qualification.

\section{A POLÍTICA DE EXTENSÃO NO IFRN}

Em novembro de 2017 o Conselho Superior do IFRN, CONSUP, aprovou a resolução $n$. 58/2017, que define um Regulamento das Atividades de Extensão no âmbito da referida instituição. De acordo com tal resolução, "a Extensão é um processo educativo, cultural, político, social, científico e tecnológico que promove a interação dialógica e transformadora entre as instituições e a comunidade externa, levando em consideração a territorialidade." (IFRN, 2017). Como podemos observar, essa definição contém uma concepção complexa e essencial de ser analisada para o desenvolvimento de projetos extensionistas no atual contexto da educação pública brasileira. Para melhor compreendermos essa concepção de Extensão do IFRN, partimos de uma análise qualitativa dos principais documentos institucionais, como o Projeto Político Pedagógico, doravante indicado como PPP (IFRN, 2012), a legislação vigente, como as leis n. 9.394/96 e n. 11.892/2008 e a experiência do Grupo de Pesquisa em Multireferencialidade, Educação e Linguagem (GPMEL) com os projetos de colaboração pedagógica entre o IFRN e escolas públicas do estado do Rio Grande do Norte, desenvolvidos desde 2013. Tais projetos adotam como fundamentação teórica, sobretudo, os estudos de Damiani (2008), Freire (2002) 
e Sancho (2006) e articula conhecimentos e práticas do campo das tecnologias para efetivar uma integração formativa entre todos os envolvidos. Assim, com base nesses fundamentos, buscamos analisar as contribuições relativas a um projeto de extensão desenvolvido no IFRN no que tange à formação docente e à qualidade de ensino junto às escolas partícipes.

Para tal, tomamos por pressuposto o princípio da indissociabilidade entre ensino, pesquisa e extensão, conforme preconizado na LDB 9.394/96 e no PPP (IFRN, 2012). Dessa forma, ainda que estejamos enfocando a análise da política de extensão, consideramos que ela se desenvolve tanto a partir de um inter-relacionamento do ensino e pesquisa da mesma instituição, como pode refletir e repercutir em transformações da própria tríade. Nesse sentido, levamos em consideração que os documentos institucionais e os textos legais são reflexo das políticas construídas historicamente pelos diversos sujeitos partícipes da instituição em relação com os contextos socioeconômicos e culturais mais amplos da região e do país. Com isso, sabemos que a política de extensão do IFRN teve início antes da própria institucionalização dos IFs (Institutos Federais).

De toda forma, a mais recente institucionalidade, IFs, já têm construído uma cultura organizacional que articula esse histórico com as novas e crescentes demandas (PACHECO, 2011). Por isso, o PPP (IFRN, 2012) e a resolução n. 58/2017 são documentos essenciais de serem analisados para o desenvolvimento das ações extensionistas do IFRN. Sabemos que as universidades públicas brasileiras têm uma significativa experiência no campo da política de extensão e a Lei 11.892/2008, de criação dos IFs, aproxima a estrutura das instituições de educação profissional e tecnológica do modelo universitário. Contudo, "os princípios e finalidades da educação profissional e tecnológica em articulação com o mundo do trabalho e os segmentos sociais, e com destaque para a produção, o desenvolvimento e a propagação de conhecimentos científicos e tecnológicos" dão o tom de especificidade e grande complexidade ao trabalho dos IFs (inciso IV, art. $7^{\circ}$ ).

No caso do IFRN, de acordo com o PPP (IFRN, 2012, p. 218), a extensão torna-se o meio essencial de interação com o entorno da instituição para a construção de saberes de cada profissionalidade. Destacamos o trecho a seguir desse documento que exprime mais elementos da concepção de extensão:

A extensão, como via de interação com a sociedade, constitui-se em um elemento de mão dupla indispensável tanto para o Instituto conhecer a realidade sociocultural, econômica e política de seu entorno quanto para a comunidade ter acesso ao saber produzido no e pelo Instituto. Portanto, no arcabouço da extensão, a educação, a ciência e a tecnologia devem estar articuladas, de modo a agregar saber e fazer, a socializar conhecimentos, a possibilitar trocas de saberes (acadêmicos, experienciais e populares) e a contribuir, à luz de um saber fazer reflexivo e crítico, com o desenvolvimento da práxis profissional. (IFRN, 2012, p. 218) 
Portanto, o entorno social do IFRN éum agente importante pela horizontalização das relações, a partir da articulação de uma proposta educacional dialógica, de "práticas favorecedoras da emancipação dos sujeitos - as bases da autonomia, do protagonismo identitário, da participação social e do respeito à diversidade e à diferença" (IFRN, 2012, p. 217). Diante disso, consideramos que autores como Damiani (2008), Freire (2015) e Sancho (2006), contemplados nos projetos do GPMEL têm importantes elementos de articulação com essa perspectiva de extensão do IFRN. Da mesma forma, a articulação das tecnologias da informação e comunicação com o cotidiano escolar e a própria ação extensionista tem favorecido a integração das instituições e sujeitos partícipes. Sobre isso, detalharemos a análise nos tópicos a seguir.

\section{A DIALOGICIDADE E A COLABORAÇÃO NA POLÍTICA DE EXTENSÃO}

Damiani $(2008$, p. 214) realizou análise tanto da etimologia do trabalho colaborativo como de algumas experiências desenvolvidas nesse campo. A autora parte da compreensão de que: "grupos colaborativos são aqueles em que todos os componentes compartilham as decisões tomadas e são responsáveis pela qualidade do que é produzido em conjunto, conforme suas possibilidades e interesses".

Damiani (2008) aponta Vygotsky (1998) como um dos estudiosos que explica os processos cognitivos de desenvolvimento e aprendizagem envolvidos na perspectiva de trabalho colaborativo. De acordo com Vygotsky (1998), ações individualizadas impossibilitam os processos interpsicológicos que impulsionam um série de outros processos intrapsicológicos, os quais geram uma aprendizagem mais significativa. Engeström (1994) e Lave e Wenger (1991) são outros autores que também defendem a importância de ações socialmente construídas, sem hierarquização e de co-responsabilidade para uma melhor formação cidadã dos sujeitos.

No caso do trabalho docente, Parrilla e Daniels (2004), identificaram que o trabalho individual gera uma série de problemas aos profissionais: insegurança, dificuldades em tomar iniciativa, cansaço e até falta de esperança em driblar os desafios do trabalho pedagógico. Isso tudo é agravado quando somado às precárias condições de trabalho de muitos docentes tanto no Brasil, como em outros países (PIMENTA, 2005; FULLAN e HARGREAVES,2000).

Considerando a perspectiva contextual mais ampla da condição de trabalho docente, sabemos que tal profissão não está livre das pressões do modelo capitalista de produção que individualiza as responsabilidades, como forma de limitar os espaços de participação crítica e transformadora dos cidadãos. Da mesma forma, entre estudantes, o princípio do individualismo é disseminado através de várias práticas pedagógicas, travestido de valor de justiça e igualdade, além de fator de motivação e sucesso profissional. De acordo com Dubet (2004, p. 541), a origem do individualismo e valorização da meritocracia é de origem liberal e não visava: 
[...] criar um reino de igualdade de oportunidades, e sim permitir uma certa mobilidade social graças à escola para as classes médias e uma minoria do povo. Esse elitismo republicano (é assim que ele é chamado na França) repousa, portanto, sobre um princípio de mérito bastante parcial, e o fato de que muitos professores tenham sido bolsistas não nos deve levar a uma nostalgia que não se sustenta além das classes médias escolarizadas, que tudo devem à escola.

Como explica Dubet (2004, p.541), com a escolarização obrigatória e o princípio meritocrático os estudantes continuam a competir, mas, agora, no interior da escola. Assim, somente "[...] os "dotados" conseguem ter sucesso e concluir o curso, graças ao sistema de bolsas", os demais, além de enfrentarem as dificuldades de permanência e êxito provenientes das diferenças socioeconômicas e culturais, ainda são considerados fracassados por falta de mérito - capacidade e esforço individuais. Tais estratégias também fazem parte de uma ideologia neoliberal, como meio de justificativa dos privilégios de classe. E, como atenta Oliveira (2014, p.44-45):

Os teóricos neoliberais, ao defenderem categorias como a flexibilidade, participação, formação abstrata e polivalência, autonomia, etc., estão muito distantes de um modelo de formação politécnica que contribua para a formação de um sujeito capaz de intervir na realidade, sob o aporte de uma visão menos fragmentada. Indivíduo capaz de moldar a realidade envolvente aos interesses coletivos. Vale dizer que categorias como participação e autonomia, ao serem apresentadas pelos neoliberais, adquirem outro conteúdo político, revestindo-se de uma dimensão estritamente econômica.

Nesse sentido, a vertente neoliberal tem disseminado pensamentos e estratégias que, como alertava Bourdieu (1998, p. 137) tenta destruir.

[...] todas as estruturas colectivas capazes de colocar obstáculos à lógica do mercado puro: a nação, cuja margem de manobra não cessa de diminuir; os grupos de trabalho, com, por exemplo, 
a individualização dos salários e das carreiras em função das competências individuais e a atomização dos trabalhadores que daí resulta; os colectivos de defesa dos direitos dos trabalhadores, sindicatos, associações, cooperativas; a própria família, que, através da constituição de mercados por classes de idade, perde uma parte do seu controlo sobre o consumo.

Diante disso, vemos que os projetos do grupo GPMEL, que adotam a perspectiva colaborativa de formação docente e integração entre escolas públicas, são ações extensionistas que podem contribuir para o desenvolvimento de habilidades docentes mais coletivistas, em que o diálogo e o apoio mútuo sirvam como bases para a melhoria das práticas pedagógicas da Educação Básica. Retomando a reflexão de Bourdieu (1998, p. 148) sobre as práticas neoliberais, vemos que é importante alimentarmos a esperança de resistência e desconstrução do individualismo nas próprias instituições públicas e seus agentes que devem:

[...] trabalhar para inventar e construir uma ordem social que não tenha por única lei a busca do interesse egoísta e a paixão individual do lucro, e que prepare o caminho a colectivos orientados no sentido da busca racional de fins colectivamente elaborados e aprovados. Entre estes colectivos, associações, sindicatos, partidos, como não atribuir um lugar especial ao Estado, [...], capaz de controlar e de tributar eficazmente os lucros obtidos nos mercados financeiros e, sobretudo, de contrabalançar a acção destruidora que estes últimos exercem sobre o mercado de trabalho, organizando, com a ajuda dos sindicatos, a elaboração e a defesa do interesse público que, quer se queira quer não, não sairá nunca, nem sequer ao preço de algumas falsidades de escrita matemática, da visão do contabilista (noutra época diríamos do "merceeiro") que a nova crença apresenta como a forma suprema da realização humana.

Pensando na construção dessa resistência e da esperança através de uma prática profissional mais colaborativa, a reflexão de Freire no livro Extensão ou comunicação?, publicado originalmente em meados do ano de 1968, no Chile, sobre o trabalho de extensionistas agrários e camponeses é fundamento importante para a compreensão de processos educativos, sobretudo, da política de extensão ainda nos dias atuais. 0 autor (2015) parte da concepção de educação dialógica e analisa os limites do termo/concepção da Extensão, levando em conta as perspectivas das relações culturais entre o extensionista e o educando, no caso, o agrônomo e o camponês. 
Do ponto de vista semântico, de acordo com Freire (2015, p.17), o termo extensão evidencia a ideia de estender algo a alguém. No caso, nas palavras dele, seria "a extensão de seus conhecimentos e de suas técnicas [do extensionista] [...] para que possam transformar melhor o mundo em que estão". Mas, articulada a essa ação, Freire (2015) observa que há forte viés messiânico, hierárquico e mecanicista nessa transmissão de conhecimentos, ou seja, muitas vezes o extensionista exerce uma "invasão cultural".

A invasão cultural, segundo o autor, nesse contexto, se dá pela negação dos conhecimentos prévios do educando/camponês e pela prescrição/persuasão das técnicas e conhecimentos científicos por parte do extensionista, sem uma problematização, um diálogo real e uma construção crítica de conhecimentos, entre as partes, educadores e educandos. Nas palavras de Freire $(2015$, p.28):

Este é um modo estático, verbalizado, de entender o conhecimento, que desconhece a confrontação com o mundo como a fonte verdadeira do conhecimento, nas suas fases e nos seus níveis diferentes, não só entre os homens, mas também entre os seres vivos em geral.

Além da dissonância com os pressupostos educativos mais democráticos, a prática da extensão como invasão cultural recai também na desconsideração das possibilidades de estratégias e resistência constitutivas da própria estrutura cultural. De acordo com Freire (2015), há uma verdadeira solidariedade entre os sujeitos educandos/agrônomos de reagirem contra determinadas ações quando sentem que estão ameaçadas suas crenças, costumes e formas de compreensão do seu ao redor - uma "sistema de referências". Ou seja, os objetivos de um projeto de extensão em prol de uma transformação social somente é possível se forem desenvolvidos através de relações mais horizontais com a colaboração de todos os sujeitos partícipes.

Nesse sentido, a "comunicação" seria, para Freire (2015), a opção mais favorecedora de uma prática extensionista de cunho educativo, de fato. Na perspectiva da comunicação, o educando deve participar numa postura curiosa de busca, "invenção e reinvenção" perante o mundo, implicando na dialogicidade entre os sujeitos extensionista e educando. É claro que, o que se entende por "invenção e reinvenção" não se trata de percorrer novamente todos os passos históricos do conhecimento científico (FREIRE, 2015), mas desenvolver o sensocrítico e articular significativamente os saberes e habilidades a serem apreendidos. Nas palavras do autor:

O que se pretende com o diálogo, em qualquer hipótese (seja em torno de um conhecimento científico e técnico, seja de um 
conhecimento "experiencial"), é a problematização do próprio conhecimento em sua indiscutível reação com a realidade concreta na qual se gera e sobre a qual incide, para melhor compreendê-la, explicá-la, transformá-la. Se 4 x 4 são 16, e isto só é verdadeiro num sistema decimal, não há de ser por isto que o educando deve simplesmente memorizar que são 16. É necessário que se problematize a objetividade desta verdade em um sistema decimal (FREIRE, 2015, p.65).

De todo modo, um dos desafios da prática da comunicação é a questão do tempo, debatida pelo próprio Freire (2015, p.45) - objeção comum dos agrônomos - "seus resultados são lentos, duvidosos, demorados. Sua lentidão, apesar dos resultados que pudesse produzir não se concilia com a premência do país no que diz respeito ao estímulo à produtividade".

Nesse sentido, sabemos que boa parte das práticas extensionistas das instituições públicas de ensino são reguladas pelo tempo institucional. Quer dizer, dependem do calendário letivo, de editais de apoio, de carga-horária de trabalho dos profissionais e vinculação acadêmica nos cursos de formação profissional. Diante disso, a proposição freiriana é desafiadora num contexto de hiperburocratização do trabalho escolar e das crescentes demandas de produtividade sobre professores e estudantes. Ainda assim, as práticas extensionistas fundamentadas no princípio dialógico detêm maior possibilidade de efetiva capacitação profissional e transformação dos partícipes (FREIRE, 2015). Além do que, é no trabalho coletivo/colaborativo, portanto, dialógico que se viabiliza maiores possibilidades de resistência contra as estratégias neoliberais de perda de criticidade, transformação social e autonomia cidadã.

Com isso, a formação profissional docente não se atrela ao mero atendimento dos propósitos empresariais. O papel da educação pública nesse contexto, e de uma instituição que atua desde a Educação Básica à Pós-graduação, como o IFRN, seria o de contrapôr-se à mercantilização, atuando e formando para o mundo, pensando o ser humano em sua omnilateralidade, desconstruindo as perspectivas hegemônicas.

\section{AS TECNOLOGIAS PARA A EDUCAÇÃO QUE QUEREMOS NO FUTURO'}

Diversos autores, tais como Kenski (2007) e Mercado (2013) discutem metodologias para que as tecnologias, de fato, sirvam de impulso para um melhor trabalho docente. Seja como um propulsor de inovação tecnológica, como forma de diversificar o trabalho dentro e fora dos muros da escola, ou ao menos como ferramenta auxiliar do trabalho educativo

1 Parte das reflexões aqui apresentadas estão também disponíveis no artigo Technologies in the classroom: reflecting about teaching, research and extension on public schools of Rio Grande do Norte, Brazil, apresentado na International Academic Conference on Teaching, Learning and e-learning, em Budapeste, marco de 2018. 
no processo de planejamento, para preparar as aulas e formular mecanismos de avaliação, relatórios e feedback.

Também podem ser verificadas várias modalidades, teorias e plataformas que reafirmam que a mediação tecnológica pode trabalhar efetivamente para melhorar os processos de ensino e aprendizagem, tais como o ensino híbrido (do inglês blended learning) e a classe de aula invertida (flipped classroom). Estudiosos como Morin (2011) sempre afirmam a necessidade iminente de mudar metodologias e de despender esforço na capacitação do docente para que os espaços educativos não mais estejam vinculados às antigas formas tradicionais da famigerada e retrógrada "transmissão de conhecimento".

Sobre estes aspectos vemos a importância do trabalho de Sancho (2006), que indica sete axiomas para converter as TICs em motor de inovação tecnológica. Apesar de ser uma concepção debatida há mais de dez anos, esse pensamento ainda é atual, uma vez que partem da necessidade de ter uma infraestrutura tecnológica que favoreça o trabalho docente, expandindo o conceito/estrutura de sala de aula, como o enfoque construtivista, por exemplo. Afinal, o professor pode se capacitar, ter ideias inovadoras para mudar sua metodologia em sala de aula, mas, se o corpo gestor da instituição não estiver articulado com a proposta, suas propostas podem receber um "banho de água fria" ao invés de incentivo.

Existem também outras realidades que corroboram com possíveis barreiras para o trabalho docente. Pouco tempo para planejamento e capacitação é, por exemplo, um aspecto importante a ser considerado. Com a realidade salarial do professor brasileiro, chega a ser mandatório que ele tenha mais de um vínculo profissional, muitas vezes em duas, três ou mais escolas. Desta forma, fica pouco tempo para as outras "obrigações", como a necessidade de capacitação constante e mesmo o planejamento das aulas, as correções, elaboração de atividades, provas e, claro, os afazeres de sua vida pessoal.

Logo, com todo este panorama, pensar em culpabilizar o docente sobre o mal uso das tecnologias em sala de aula não pode (nem deve) ser uma opção, afinal existem inúmeros outros fatores a serem levados em consideração, este artigo se debruça sobre apenas alguns deles. Pensar na educação do futuro requer uma visão mais ampla do presente, fazendo uma análise da atual conjuntura em que estamos como sociedade, seu aspecto multidimensional e sua complexidade.

Morin (2011) discute de forma pertinente sobre a educação do futuro articulando sete saberes que necessitam ser incluídos na condição humana. Tais saberes versam sobre o que é necessário desenvolver acerca do conhecimento humano, seus processos e suas modalidades. Implicam em um trabalho que retroaja sobre as características mentais, cerebrais e até mesmo culturais dos conhecimentos do homem.

Morin (2011) afirma que as tecnologias são ferramentas importantes na mundialização da sociedade e isso pode ser positivo ou negativo, dependendo da forma como essa sociedade se encontra e se projeta no e para o mundo. Como estamos numa era planetária, acabamos "submersos na complexidade do mundo - as incontáveis informações sobre o mundo sufocam 
nossas possibilidades de inteligibilidade" (MORAN, 2011, p.55). As telecomunicações, o turbilhão de informações e a internet nos envolve nesta era planetária, nos unificando e desterritorializando os espaços de vivência. Entretanto, como o mesmo autor afirma, apesar da mundialização nos unificar, ela também pode suscitar o efeito contrário, de balcanização. Portanto, a reflexão também deve ser direcionada a entender essa complexidade do desenvolvimento não somente material, bem como perceber aspectos intelectuais, morais, afetivos, entre outros. E essa compreensão deve ser do todo, bem como das partes deste mundo abstruso e rizomático. Portanto, é importante termos absorvido bem a consciência antropológica, ecológica, cívica, terrena e espiritual da condição humana.

Um pensamento contextualizado é o que deve nos levar a refletir sobre a utilização das tecnologias na escola e, a partir daí, encontramos alguns aspectos que proporcionem mudanças significativas nos processos de ensino e aprendizagem. Assim, uma questão importante é a gestão dos espaços e do tempo, porque, diferentemente do que acontece na rede mundial de computadores, na educação presencial a temporalidade e a espacialidade são mais rígidas, controladas e muitas vezes limitadas a um quantitativo de indivíduos. Estas características nos trazem alguns questionamentos que versam sobre a própria hierarquia da escola e sobre como ocorre o diálogo entre a gestão, os professores e os alunos e a liberdade que o professor tem para atuação, que deve ocorrer em conformidade com os conteúdos fixos que devem ser trabalhados em sala de aula e de forma condizente com a política e o projeto da instituição de que o professor faz parte.

A internet, por outro lado, apresenta um quadro de espaço e tempo mais amplo, mais flexível e que abrange um número maior de indivíduos. Nela não há uma hierarquia, todos nós temos voz igual para expor nossos pensamentos, o que pode ser positivo sob a perspectiva da inclusão e da diversidade, mas pode ser perigoso quando se pensa no tipo e na qualidade da informação que circula. É imprescindível, nesse contexto, fazer uma reflexão crítica sobre as informações que merecem, ou não, serem transformadas em conhecimento. Com este panorama podemos tirar o melhor da educação formal e da informal, seja ela presencial, híbrida ou totalmente a distância.

Afinal, tudo que é produzido em sociedade pode ser útil no processo de aprendizagem, entretanto, para processos formais, faz-se necessário uma transposição didática e, para isso, um mediador. Chevallard (1991, p. 153-214) afirma que:

Os processos transpositivos-didáticos e, mais genericamente, institucionais - são, imagina-se, a mola essencial da vida dos saberes, de sua disseminação e de sua funcionalidade adequada. [...] Um saber dado $S$ se encontra em diversos tipos de instituição I, que são para ele, em termos de ecologia dos saberes, respectivos habitats diferentes. Desse modo o saber ocupa 
regularmente nichos muito diferentes, logo as relações entre os saberes e as instituições também são diversas. Correlativamente, a maneira que os agentes da instituição vão "manipular" esse saber será variável.

Conforme o autor, os saberes precisam ser recontextualizados para que a informação se constitua em conhecimento por meio do processo de mediação didática e a linguagem neste quesito assume um papel fundamental, principalmente quando tratamos de tecnologias para educação, que são sustentadas pela comunicação entre os usuários e que apresentam diversas linguagens. Quando surge uma nova tecnologia ela vem arraigada a novos conflitos, como também a novas possibilidades para a educação formal, pois elas têm as mais diversas finalidades, mas, com a transposição adequada, podem ser capazes de ampliar a sua utilização no ramo educativo.

Quando se trata de ferramentas virtuais, elas podem ser categorizadas enquanto forma e conteúdo. A forma do virtual está atrelada aos recursos técnicos propriamente ditos, como os programas de computador e os aplicativos espalhados na nuvem. Já o conteúdo está vinculado às possibilidades que tais recursos apresentam, como mecanismos potencializadores do aprendizado (BARROS e SIMÕES, 2014). Entretanto, como já enfatizado, é preciso que haja motivação e formação para a efetiva utilização desses novos recursos e isso implicará também no nível de desenvolvimento do indivíduo para utilizar cada recurso como mecanimento de interação educacional. Logo, os ambientes tecnológicos estimulantes à interação precisam apresentar uma base cultural e ser planejados para que sejam instrumentos na construção de conhecimento. Assim como as escolas, os espaços físicos de formação, também necessitam estar preparados, sob a perspectiva da gestão e da infraestrutura física e tecnológica para utilizar esses novos recursos.

Desta forma, a escola será capaz de acompanhar as mudanças que as tecnologias trazem de forma satisfatória e de forma aplicada à tríade ensino-pesquisa-extensão e ao cenário contemporâneo embargado nas relações interpessoais, mutabilidade, colaboração, autonomia, entre outros aspectos.

\section{A PRÁTICA EXTENSIONISTA ENTRE O POSSÍVEL E $O$ DESEJADO: INSTITUIÇÕES E SUJEITOS EM COLABORAÇÃO PELA FORMAÇÃO DOCENTE E O USO DAS TECNOLOGIAS NAS ESCOLAS}

Como mencionamos anteriormente, o GPMEL desenvolve projetos de extensão há cerca de 4 anos, a partir do apoio que a Pró-reitoria de Extensão do IFRN fornece ao lançar editais de bolsas de extensão para professores e estudantes de todos os níveis e modalidades de ensino.

Os projetos do GPMEL partem da necessidade de maior interação entre os profissionais e 
estudantes das licenciaturas do IFRN com escolas públicas de ensino fundamental e médio. Tal interação é essencial para as partes uma vez que, por um lado, boa parte dos estudantes de ensino fundamental e médio nutrem o desejo e o interesse em participar dos processos seletivos de ingresso em algum curso do IFRN, já os estudantes e professores-pesquisadores do IFRN, buscam aprofundar seus conhecimentos sobre o cotidiano escolar dos jovens das escolas ao nosso ao redor. No ano de 2017, o projeto desenvolvido foi intitulado "Práticas integrativas e colaborativas com escolas públicas do RN".

Assim, conforme tratamos no tópico inicial, os fundamentos vygotskianos de desenvolvimento proximal foram basilares para essa interação: inicialmente há um processo de aproximação e consulta às escolas de ensino fundamental e médio para consensuar o desenvolvimento das ações extensionistas. Somente a partir desse consenso, parte-se para a problematização e diálogo sobre que conteúdos e atividades são importantes para a escola e são possíveis de serem desenvolvidos pela equipe do projeto. Conforme a proposição freiriana (2015), essa fase do projeto é essencial, como forma de não recair numa invasão cultural. Ou seja, é importante compreender-se que a equipe extensionista não está em posição hierárquica superior, mas coloca-se também em posição de aprendiz, de curiosidade aguçada e respeitosa frente ao contexto próprio de cada ambiente escolar. Nesse sentido, ainda que, quando falamos em cotidiano escolar, em linhas gerais, imaginemos uma série de semelhanças entre várias escolas, ao determo-nos atenciosamente na fala de cada estudante, docente, gestor, em cada sala de aula, percebemos uma série de peculiaridades, uma diversidade cultural que repercute em diálogos bastante diversos também. Nesse sentido, a experiência com a diversidade para os estudantes de licenciatura é uma experiência de formação profissional que contribui com a aquisição de saberes e habilidades mais coletivistas, de ações negociadas, dialogadas e de compartilhamento de saberes e novas perspectivas de ensino-aprendizagem. Dessa forma, o trabalho colaborativo nos projetos de extensão permite a articulação de conhecimentos teóricos e metodológicos, bem como são indispensáveis para o fortalecimento do trabalho educacional democrático, público, gratuito e de qualidade.

Para as escolas de ensino fundamental e médio, por outro lado, a ocasião de pensar sobre que necessidades e interesses podem ser atendidos no projeto de extensão é uma situação que foge ao cotidiano e pode se transformar em momento de inovação e expansão das expectativas da trajetória escolar. Nesse sentido, o Programa de Iniciação Tecnológica e Cidadania (PROITEC) ${ }^{2}$ é outro programa do IFRN que colabora com a extensão desenvolvida pelo GPMEL, na medida em que disponibiliza material didático de língua portuguesa, matemática e cidadania para as escolas de ensino fundamental. Documento do IFRN, o Plano de Desenvolvimento Institucional (IFRN, 2009, p.13) avalia que tal programa “[...] contribui para elevar os níveis da qualidade do

2 O Programa de Iniciação Tecnológica e Cidadania (PROITEC) do IFRN é um curso de educação a distância em que os estudantes matriculados no nono ano do Ensino Fundamental em escolas públicas, inscritos no exame de seleção para entrada no Ensino Médio do IFRN recebem gratuitamente material didático contemplando os conteúdos de Português, Matemática e Cidadania que são avaliados no exame de seleção do IFRN. O material didático compreende um livro com 10 unidades didáticas, um DVD com 10 vídeo aulas e um livro de exercícios com testes explicados. 
ensino em todo o Estado. [E,] Tem-se, assim, um importante meio para garantir que a inclusão social seja feita com qualidade e responsabilidade".

Diante disso, o GPMEL vem trabalhando nessa perspectiva há quatro anos, mas a cada ano há uma mudança das práticas e conteúdos, em virtude tanto dos interesses como das condições disponíveis nas escolas de ensino fundamental e médio e da própria estrutura do projeto. Quer dizer, a cada ano o número de estudantes de licenciatura e as áreas de ensino se modificam. Portanto, as ações são acordadas de acordo com essa disponibilidade também. De todo modo, o trabalho colaborativo também tem propiciado atividades e oficinas mais interdisciplinares e, sobretudo, focalizando o uso de tecnologias da informação e comunicação na sala de aula.

No ano de 2017, o projeto concentrou-se em duas escolas de Natal e Parnamirim/RN e buscou articular ensino, pesquisa e extensão desenvolvendo o projeto de extensão por meio de oficinas ministradas pelos estudantes de graduação do IFRN, sob orientação de docentes de cada área, e também desenvolvendo o projeto de pesquisa "O uso dos Recursos Tecnológicos na Educação Básica: analisando a concepção e o uso das tecnologias entre professores e estudantes de escolas do Rio Grande do Norte". No âmbito da pesquisa, procurou-se compreender a infraestrutura disponível nas escolas colaboradoras para o uso de tecnologias pelos professores, enquanto no âmbito da extensão, buscou-se colaborar, por meio de oficinas, com o desenvolvimento de conteúdos específicos conforme a solicitação da equipe de cada escola, para estudantes da Educação Básica e também, oferecer capacitação para os docentes em dois temas que haviam sido reivindicados nos anos anteriores de desenvolvimento dos projetos: Uso de tecnologias na sala de aula e Educação Inclusiva.

Durante as visitas iniciais às escolas, a equipe do GPMEL pode conhecer a infraestrutura física e o ambiente escolar, equipe técnico-pedagógica, docentes e alguns estudantes. As escolas contam com um laboratório de informática (cada uma), mas a manutenção desses laboratórios é irregular e a quantidade de máquinas não é suficiente para uma turma de 40 estudantes.

As oficinas oferecidas aos estudantes incluíram aspectos bastante específicos de sua formação que foram indicados pelos professores de cada escola como mais problemáticos em seu desenvolvimento, tais como Produção do texto argumentativo, Leitura e interpretação de textos, Educação ambiental, Degradação do solo. O tempo dedicado a cada oficina foi determinado por cada escola dentro de seu calendário letivo, discutido em grupo pelos componentes do GPMEL e desenvolvido conforme a disponibilidade de todos. As oficinas poderiam ter até $12 \mathrm{~h}$, mas devido às dificuldades do calendário letivo, acabaram por ocorrer, nas escolas, em períodos de 6 a 8 h.

Evidentemente, o grupo de professores e estudantes reconhece a impossibilidade de desenvolver uma formação aprofundada dentro dessa carga horária, mas também compreende que os estudantes dessas escolas, imersos em seu cotidiano escolar, raramente têm a oportunidade de lidar com situações que fujam à rotina e desenvolver oficinas, com materiais concretos, a partir da perspectiva teórico-didática de pessoas diferentes daquelas 
com quem eles convivem dentro do cotidiano escolar pode funcionar como elemento motivador e, sob essa perspectiva, o trabalho tem sido sempre aprovado pelas escolas e pelos seus estudantes. Essa aprovação pode ser percebida ao final de cada projeto, em seu momento de culminância.

O final de cada projeto desenvolvido pelo GPMEL ocorre não só por meio de uma avaliação do próprio grupo, mas com a organização de um encontro entre todos os partícipes, equipe gestora, professores e estudantes das escolas colaboradoras e professores, estudantes, bolsistas do IFRN. Nesses encontros são organizados momentos culturais, mesas compostas com a equipe gestora/docentes das escolas e mesas compostas com os professores/ estudantes que desenvolveram as oficinas do projeto. 0 objetivo dessas mesas é dimensionar os aspectos positivos e negativos do projeto nas escolas, apresentar os resultados das pesquisas aplicadas à comunidade escolar envolvida e também, socializar, apenas permitir o encontro e o diálogo entre todos os partícipes.

Observa-se, nesses encontros, que há uma grande vontade de mudança e colaboração por parte dos profissionais. Tanto na receptividade em abarcar a participação do IFRN na escola, quanto nas contribuições com o instrumento de pesquisa.

Percebe-se também uma lacuna na falta de estrutura e preparo dos profissionais e da escola como um todo para utilização das tecnologias, entretanto, com o trabalho de colaboração intrínseco aos projetos, as faltas eram preenchidas por aqueles que poderiam contribuir. Em resposta ao questionário de pesquisa ${ }^{3}$ aplicado nas duas escolas em que o GPMEL atuou em 2017, quando questionados sobre uma experiência de uso de recursos digitais na escola, os professores indicaram, entre os principais obstáculos: não conhecimento do sistema operacional disponibilizado (Linux), a quantidade e a qualidade dos recursos disponibilizados, a necessidade de montar e desmontar o equipamento, no caso do projetor, que serve a mais de uma sala e a mais de um docente, pois a escola só dispõe de um equipamento, a falta de sinal de internet na sala de aula.

As respostas dos docentes deixa-nos ver que a infraestrutura de que eles dispõem não permite muitas atividades inovadoras ou o uso regular de tecnologias em sala de aula. Também deixa clara a necessidade de capacitação para o uso das tecnologias na educação. O GPMEL tem tentado, por meio de seus projetos de extensão e pesquisa não só identificar as demandas de formação, mas colaborar com a melhor capacitação dos docentes no uso das tecnologias.

Em depoimentos informais, os docentes afirmaram que gostariam da continuidade do projeto nas escolas em outras oportunidades, o que reforça o argumento anterior e impulsiona o trabalho do GPMEL que idealiza a proposta deste projeto a cada ano. Os desafios são muitos, mas a força motora de querer mudar também, como pode ser observado pelo depoimento de um dos docentes:

3 Resultados parciais dessa pesquisa foram apresentados e publicados em Anais do Congresso Nacional de Educação: MOTTA, Thalita Cunha; LEMOS, Elizama das Chagas; CAVALCANTE, Ilane Ferreira; SANTOS, Onã de Araújo. Conhecendo o uso de recursos tecnológicos em escolas de Educação Básica na cidade do Natal e de Parnamirim/RN, 2017, p. 1 a 11. Disponível em: https://editorarealize.com.br/revistas/conedu/anais.php. 
[...] Apesar das possibilidades de trabalho e inovações em sala de aula serem inúmeras, podemos afirmar que na balança "possibilidades x desafios" da implantação das novas ferramentas tecnológicas nas escolas, os desafios ainda vêm se mantendo na linha de frente, lamentavelmente. Nós, enquanto docentes de uma escola pública e comprometidas com a educação de qualidade e moderna, continuaremos nessa batalha, enfrentando esses entraves e vislumbrando as possibilidades, para que olhemos as mudanças ao nosso redor e nos comprometamos com o redirecionamento demandando pela juventude da 'Era virtual'.

Logo, fica claro o comprometimento dos docentes e das escolas participantes em vislumbrar as possibilidades, atuando de forma colaborativa para fazer com que a educação pública brasileira tenha a qualidade que desejamos e as tecnologias sejam utilizadas de forma plena em todo o processo e por todos. Sabemos que, mesmo que não andemos a passos tão largos quanto gostaríamos - e como outras áreas parecem andar mais favoravelmente - não significa que deixamos de caminhar. Caminhamos de mãos dadas.

\section{5. À GUISA DE CONCLUSÃO}

As TIC ocupam nossas vidas em inúmeros aspectos de ordem social, econômica, da segurança... Por exemplo, na área da saúde, podemos ver saltos holísticos que aconteceram em alguns procedimentos cirúrgicos, que são realizados hoje em dia utilizando até mesmo equipamentos vídeo-transmissores para que sejam menos invasivos e para que a recuperação dos pacientes seja mais rápida. A questão que sempre nos inquieta é: por que a educação não acompanha esta mesma evolução? Afinal, é perfeitamente compreensivo o estado atual em que a sociedade se encontra, as inúmeras soluções encontradas em rede, trazendo inúmeras possibilidades para implementação em sala de aula as inovações, sem mencionar o anseio do próprio docente e do aluno em ter algo de diferente, algo inovador, algo que impulsione o ato de construir conhecimento.

A inter-relação entre educação e tecnologias é um elemento essencial na prática pedagógica atual. Nesse sentido, o meio escolar precisa se adaptar às tecnologias e tirar delas a melhor contribuição para o processo de ensino e aprendizagem.

Este artigo tentou entender um pouco o porquê dos entraves que dificultam o melhor uso das tecnologias nas escolas, refletindo sobre como questões que extravasam a realidade escolar acabam por interferir na realidade escolar, caso das políticas públicas que permitem a inserção 
das instituições de ensino superior nas comunidades por meio da extensão e de seu reflexo na experiência de uma instituição e de um grupo extensionista em particular, o GPMEL do IFRN, cujos projetos são desenvolvidos por professores e estudantes de dois campi: Natal Central e EaD.

Os projetos que ocorreram nas escolas parceiras em conjunto com o IFRN aconteceram de forma satisfatória, com contributos que serviram de análise para compreender o panorama da educação pública das duas escolas colaboradoras.

Durante a experiência de quarto anos de desenvolvimento de projetos de extensão e pesquisa, ficou claro que ainda não há oferta suficiente de formação continuada para adequação das práticas pedagógicas dos docentes. Os docentes das escolas parceiras demonstraram compreender a importância da utilização de tecnologias no cotidiano escolar, mas reconhecem as dificuldades de infraestrutura e de formação.

A experiência revela que, para que as TIC sirvam de motor impulsionador de inovação na área educativa, se faz necessário todo um sistema favorável, que muitas vezes independe da tecnologia propriamente dita. Nesse sentido, o IFRN pode atuar de forma positiva, a partir de suas experiências de extensão e pesquisa, oferecendo formação na área, mas acima de tudo, compreendendo a realidade dessas escolas e, de forma não hierárquica e colaborativa, atuando na formação de professores e estudantes das escolas parceiras e de sua comunidade interna.

\section{REFERÊNCIAS}

BARROS, D. M. V; SIMÕES, P. Educação a Distância e as Novas Estratégias Pedagógicas: ferramentas da web 2.0 e estilos de aprendizagem. Em: MILL, Daniel. Educação a Distância e Tecnologias Digitais. São Carlos: EDUFSCAR, 2014.

CHEVALLARD, Y. La Transposition Didactique. Grenoble: La Pensée sauvage, 1991.

MORIN, Edgar. Os setes saberes necessários à educação do futuro. São Paulo: Cortez, 2011.

SANCHO, J. M. et al. Tecnologias para transformar a educação. Porto Alegre: Artmed, 2006. 200p.

BOURDIEU, Pierre. O neoliberalismo, utopia (em vias de realização) de uma exploração sem limites. In: Contrafogos: táticas para enfrentar a invasão neoliberal. Tradução Lucy Magalhães. Rio de Janeiro: Zahar, 1998.

DAMIANI, Magda Floriana. Entendendo o trabalho colaborativo em educação e revelando seus benefícios. Revista Educar: Curitiba: Editora da UFTPR, n.31, p. 213-230, 2008, p. 12-13.

DUBET, François. O que é uma escola justa? In: Cadernos de Pesquisa, v. 34, n. 123, set./dez. 
2004. p. 539-555.

FREIRE, Paulo. Extensão ou comunicação? 12 ed. Rio de Janeiro: Paz e Terra, 2002.

GIROUX. Henry. Teoria crítica e resistência em educação. Tradução de Ângela Maria B. Biaggio. Petrópolis: Vozes, 1986.

IFRN. Projeto Político Pedagógico. Disponível em: http://portal.ifrn.edu.br/institucional/projetopolitico-pedagogico. Acesso em 17 de março de 2016.

IFRN. CONSUP. Resolução n. 58/2017, define Regulamento das Atividades de Extensão.

KENSKI, Vani Moreira. Educação e Tecnologias: o novo ritmo da informação. São Paulo: Papirus, 2007.

MERCADO, Luis Paulo Leopoldo. Gonçalves, Monica Gomes. Tecnologia na escola: impasses para o uso do laboratório de informática na prática docente numa escola pública. In: Mercado, Luis Paulo Leopoldo. (Org.). Práticas pedagógicas com mídias na escola. Maceió: UFAL, 2013, p. $347-354$.

OLIVEIRA, Dalila Andrade. A política educacional brasileira: entre a eficiência e a inclusão democrática. Educação e Filosofia Uberlândia, v. 28, n. especial, p. 225-243, 2014.

PARRILLA, A.; DANIELS, H. Criação e desenvolvimento de grupos de apoio para professores. São Paulo: Loyola, 2004.

PACHECO, Eliezer (Organizador). Institutos federais: uma revolução na educação profissional e tecnológica. São Paulo: Editora Moderna, 2011.

VYGOTSKY, L.S. A formação social da mente. 6. ed. São Paulo: Martins Fontes, 1998. 